280 Tropelías. Revista de Teoría de la Literatura y Literatura Comparada, 29 (2018) José María Sicilia

\title{
EL INSTANTE
}

José María SICILIA

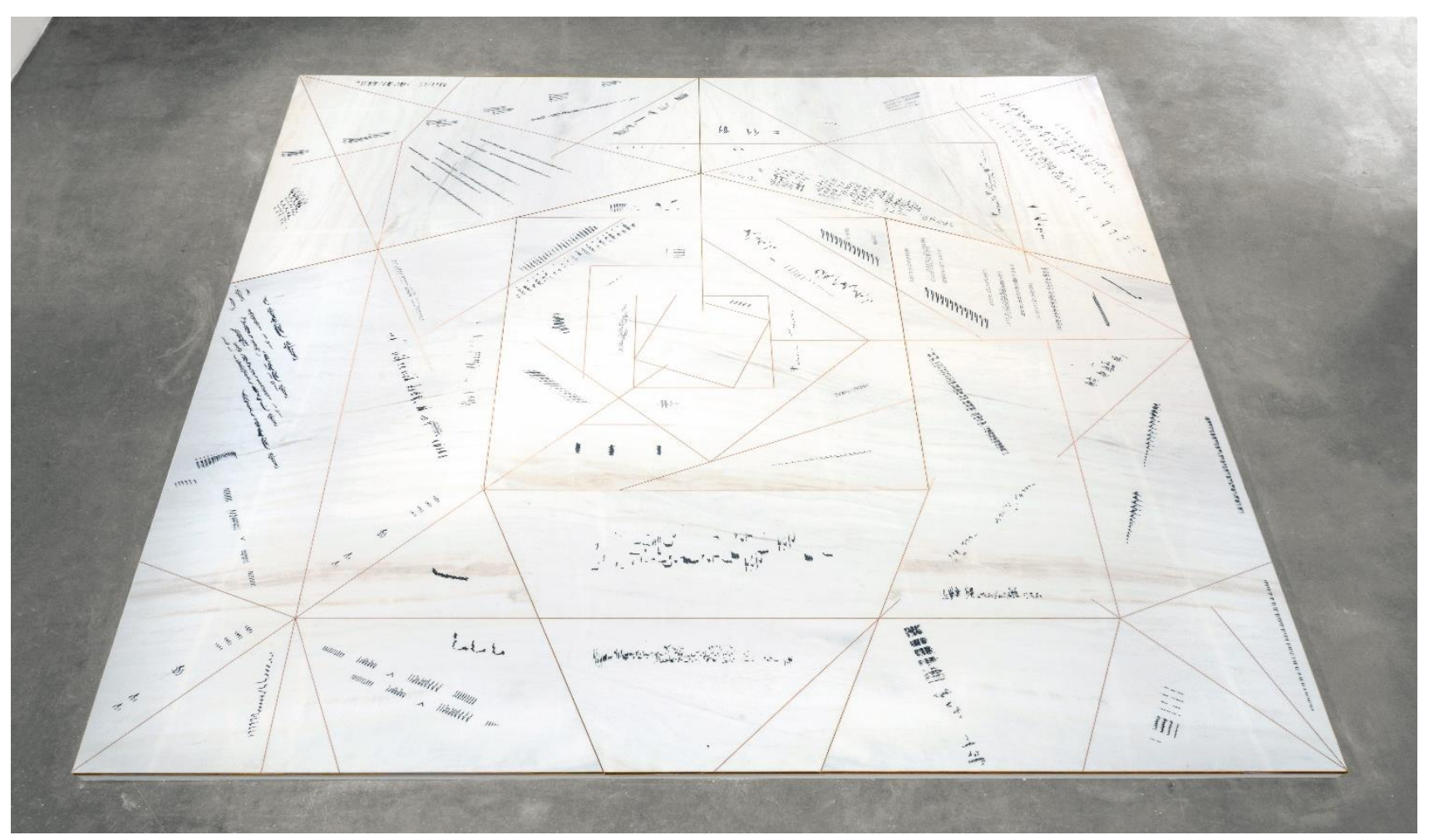


Tropelías. Revista de Teoría de la Literatura y Literatura Comparada, 29 (2018) 281

El instante
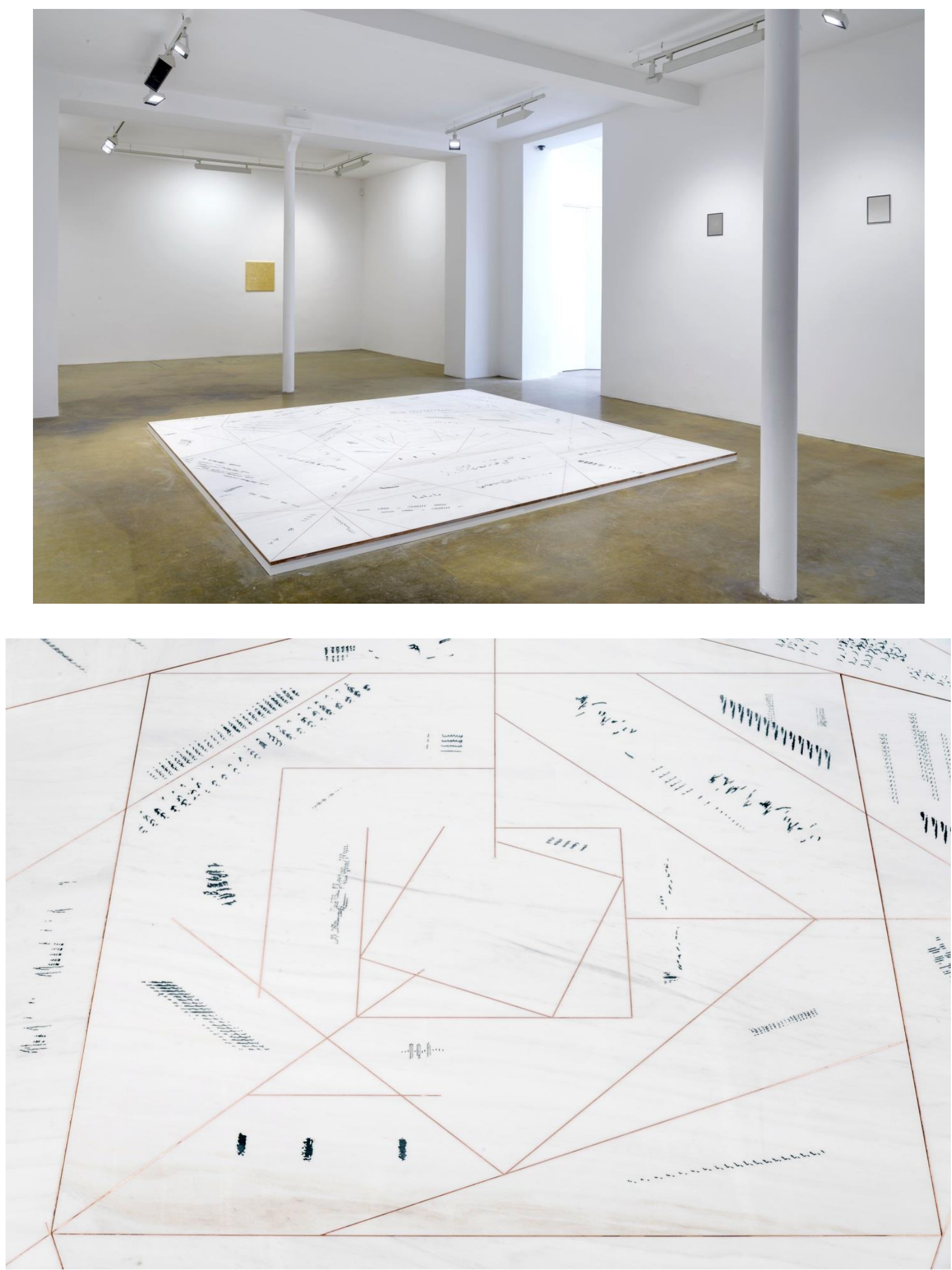

Detalles 
282 Tropelías. Revista de Teoría de la Literatura y Literatura Comparada, 29 (2018) José María Sicilia
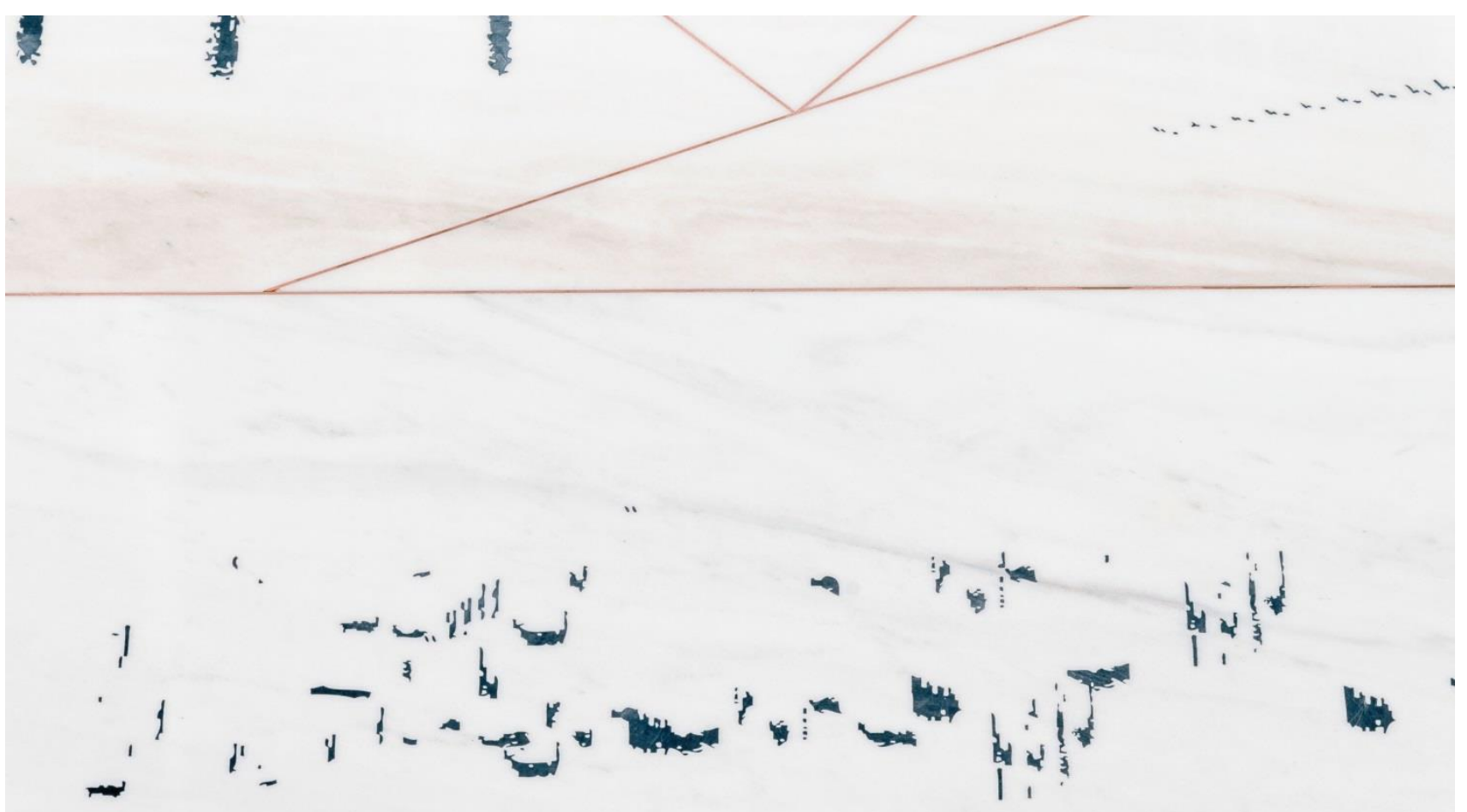

(C) José María Sicilia, VEGAP, Zaragoza, 2018

El instante, 2013

Mármol blanco Lasa pulido, polvo de mármol negro, cobre $400 \times 400 \mathrm{~cm}$ Courtesy del artista y de la Galerie Chantal Crousel, París, https://www.crousel.com/home/ Créditos fotográficos: Florian Kleinefenn 